\title{
Separative Determination of Ascorbic Acid and Erythorbic Acid by High-Performance Liquid Chromatography
}

\author{
Nobuhiko ARaKawa, Megumi ŌtsuKa, \\ Tadao KuRata, ${ }^{1}$ and Chōten InAGaKI ${ }^{2}$ \\ ${ }^{1}$ Department of Food and Nutrition, Ochanomizu University, \\ Bunkyo-ku, Tokyo 112, Japan \\ ${ }^{2}$ Laboratory of Nutrition, Kyōritsu Women's University, \\ Chiyoda-ku, Tokyo 101, Japan
}

(Received July 17, 1980)

\begin{abstract}
Summary High-performance liquid chromatography (HPLC) was applied to the determination of ascorbic acid (AsA) and erythorbic acid (ErA). The apparatus was a Shimadzu model LC-2P Liquid Chromatograph equipped with a UV detector set at $254 \mathrm{~nm}$. The separation was achieved on a LiChrosorb- $\mathrm{NH}_{2}$ column which was pre-treated with $0.1 \mathrm{M}$ ammonium monophosphate solution using a mixture of acetonitrile, acetic acid and water $(87: 2: 11, \mathrm{v} / \mathrm{v})$ as an eluant. The HPLC method has the following advantages: AsA and ErA are quantitated after being distinctly separated, analysis time per one sample is short, and AsA or ErA levels as low as $1.0 \times 10^{-2} \mu \mathrm{g}$ are detectable. Recovery experiments with dehydro-AsA and dehydro-ErA, involving reduction with $\mathrm{H}_{2} \mathrm{~S}$, gave satisfactory results.
\end{abstract}

Key Words separative determination, ascorbic acid, erythorbic acid, high-performance liquid chromatography

Erythorbic acid (ErA), also named D-araboascorbic acid, is a stereoisomer of Lascorbic acid (AsA), differing only in the spatial configuration of the hydroxyl group at carbon 5, and has the same acidic and reducing properties as those of AsA. Mainly due to its reducing properties, ErA is widely used as an antioxidant in various foods and beverages. It is generally accepted that vitamin $\mathrm{C}$ activity of $\operatorname{ErA}$ for guinea pigs is one-twentieth that of AsA. However, recent studies have shown that co-administration of ErA with AsA reduces the availability of AsA (1, 2). From the nutritional viewpoint of vitamin $\mathrm{C}$, it is very important to clarify whether ErA can partly substitute for AsA or behaves as a xenobiotic. Yet, not only the effects of ErA on utilization efficiency of AsA as vitamin C but also the interaction of ErA with AsA catabolism in vivo have not been fully elucidated, because no simple

\footnotetext{
1 荒川信彦, 大塚 恵, 倉田忠男, ${ }^{2}$ 稲垣長典
} 
and reliable method for the separative determination of AsA and ErA has been available.

Quantitative analyses of AsA and ErA in the past have depended on their separation by paper $(3,4)$ and thin layer chromatography $(5)$ and on their differences in the osazone formation rate (6). However, these methods require sample solutions of considerably higher AsA or ErA concentration, and thus, are hardly applicable to the research described above. Since ErA contents of biological samples such as liver obtained from experimental animals administered with a small dose of ErA are considered to be too small, the presence of AsA may interfere with the separation of ErA, hindering its precise estimation. The need has become evident for more sensitive and accurate methods of separately determining AsA and ErA for the purpose of clarifying the vitamin $\mathrm{C}$ function of ErA.

High-performance liquid chromatography (HPLC), demonstrated to be a versatile technique for rapid and effective separation of various biological compounds, has received little attention as a technique for separately measuring AsA and ErA.

In the present study, an acetonitrile-acetic acid-water solvent system coupled with a LiChrosorb- $\mathrm{NH}_{2}$ column has been applied to the separation of these two stereoisomers to establish a convenient routine analysis method for them. A single elution system was used from the consideration of its decisive advantages over a gradient elution system which usually takes much time and requires much complicated procedures. The results obtained demonstrate that the HPLC method is a useful technique in analyzing AsA and ErA.

\section{EXPERIMENTAL}

Reagents. Phthalic acid monoanilide (Tokyo Kasei Co., Ltd.) was used as a chromatographic internal standard. AsA, ErA and other reagents were obtained from Wako Pure Chemical Industries, Ltd. and used without further purification. The purity of acetic acid was $99.5 \%$.

Liquid chromatography. Shimadzu Du Pont LC-2P Liquid Chromatograph equipped with a SIL-1A sample injector (Shimadzu) was used and the eluate was monitored with a UV detector set at $254 \mathrm{~nm}$. A stainless steel column $(25 \mathrm{~cm} \times 4 \mathrm{~mm}$ i.d.) was packed with LiChrosorb- $\mathrm{NH}_{2}$ (E. Merck), which has amino groups chemically bound to silica gel (average particle size of $10 \mu \mathrm{m}$ ). The mobile phase was a solvent mixture of acetonitrile, acetic acid and water $(87: 2: 11, \mathrm{v} / \mathrm{v})$.

Preparation of calibration curves. A stock solution $(1 \mathrm{mg} / \mathrm{ml})$ of AsA and ErA in $2 \%$ metaphosphoric acid was diluted to $0.5 \%$ metaphosphoric acid to prepare working standards containing $0.1-0.4 \times 10^{-2} \mu \mathrm{g} / \mu \mathrm{l}$ of AsA and ErA, and besides $20 \mu \mathrm{g} / \mathrm{ml}$ of phthalic acid monoanilide as internal standard. Usually $20 \mu \mathrm{l}$ was injected. The quantities of AsA and ErA were measured by peak height relative to that of the internal standard.

Pre-conditioning of the column. The column was pretreated by passing $30-50 \mathrm{ml}$ 
of $0.1 \mathrm{M}$ ammonium monophosphate solution through the column for $30 \mathrm{~min}$, then washed with $50 \mathrm{ml}$ of water, and finally, completely equilibrated before use with the eluant at $2.8 \mathrm{ml} / \mathrm{min}$.

Calculation of the chromatographic parameters. The separation factor $(\alpha)$ and resolution $(R s)$ were calculated from the retention times using the following equation:

$$
\alpha=\frac{t_{2}-t_{0}}{t_{1}-t_{0}} \quad R s=\frac{t_{2}-t_{1}}{1 / 2\left(t_{\mathrm{w}_{1}}+t_{\mathrm{w}_{2}}\right)}
$$

where $t_{0}$, void retention time; $t_{1}, t_{2}$, retention time; $t_{\mathrm{w}_{1}}, t_{\mathrm{w}_{2}}$, peak width.

Recovery from dehydro-AsA and dehydro-ErA. Dehydro-AsA or dehydro-ErA was prepared by oxidation of AsA or ErA by 2,6-dichlorophenolindophenol. Excess pigment was removed by extracting with $n$-butanol. The solution was placed in test tubes and adjusted to $\mathrm{pH} 4.0-4.5$ with a sodium acetate solution $(1 \mathrm{M})$. The solution was treated with $\mathrm{H}_{2} \mathrm{~S}$ for $15 \mathrm{~min}$ and then kept at $4{ }^{\circ} \mathrm{C}$ overnight. Excess $\mathrm{H}_{2} \mathrm{~S}$ was removed under reduced pressure and the solution was made up to a certain volume and subjected to the HPLC analysis.

Colorimetric determination. AsA in sample solution was determined by the 2,4dinitrophenylhydrazine method (7).

\section{RESULTS AND DISCUSSIONS}

AsA, existing as an anion in the neutral $\mathrm{pH}$ region, can be separated by ionexchange chromatography $(8-10)$. The separation of AsA by reverse-phase liquid chromatography $(11,12)$ has also been reported by various workers. However, because chemical structure and ionizing properties of ErA are very close to those of AsA, their separation by simple ion-exchange chromatography seems to be difficult. For column packing, we have selected LiChrosorb- $\mathrm{NH}_{2}$, which is considered to serve not only as a weak anion exchanger but also as an adsorbent or as a stationary phase in partition chromatography.

The solvent system used in this study was a modification of the system previously developed for the TLC analysis (5) of AsA. Table 1 shows the effects of eluant composition on the retention volume and resolution. The resolution is better with a mixture of acetonitrile: acetic acid: water $(95: 0.5: 4.5)$ than with a $(90: 1: 9)$ mixture. However, upon consideration of the retention volume, the latter solvent system is more favorable for repetitive analyses than the former system. Thus, it appeared desirable to use $1.0-2.0 \%$ acetic acid for effecting the elution in a small retention volume and $90-95 \%$ acetonitrile for retaining a high resolution. These results allowed us to conclude that the composition of this solvent system giving optimal performance was acetonitrile : acetic acid : water $(87: 2: 11)$. With this solvent system, retention volume for ErA was $13.8 \mathrm{ml}$.

In cases where un-conditioned column was used, AsA and ErA were hardly eluted within $1 \mathrm{hr}$ with the solvent systems containing acetic acid at relatively low Vol. 27, No. 1, 1981 
Table 1. Effect of composition of eluant on retention volume of ErA and resolution of AsA and ErA.

Column, LiChrosorb- $\mathrm{NH}_{2}$ pretreated with $0.1 \mathrm{M}$ ammonium monophosphate; flow rate, $2.8 \mathrm{ml} / \mathrm{min}$; temp., $20^{\circ} \mathrm{C}$; eluate, a mixture of acetonitrile : acetic acid : water.

\begin{tabular}{cccc}
\hline \multirow{3}{*}{$\begin{array}{c}\text { Acetic acid } \\
(\%)\end{array}$} & 95 & 90 & 80 \\
\cline { 2 - 4 } & $63.6^{\mathrm{a}}(2.96)^{\mathrm{b}}$ & $34.7(1.83)$ & $23.0(0.92)$ \\
\hline 0.5 & $48.7(1.69)$ & $23.5(1.78)$ & $14.0(0.89)$ \\
1.0 & $33.6(1.89)$ & $16.8(2.00)$ & $10.6(0.93)$ \\
\hline
\end{tabular}

${ }^{a}$ Figures indicate retention volume $(\mathrm{ml})$ of ErA. ${ }^{\mathrm{b}}$ Figures in parentheses indicate resolution of AsA and ErA.

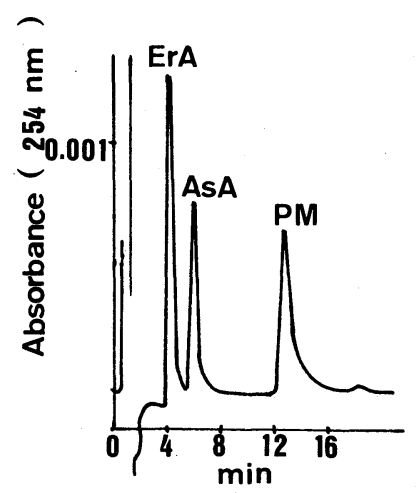

Fig. 1. Chromatogram of AsA and ErA. Column, LiChrosorb- $\mathrm{NH}_{2}$; flow rate, 3.0 $\mathrm{ml} / \mathrm{min}$; temp., $20^{\circ} \mathrm{C}$; eluant, a mixture of acetonitrile: acetic acid: water $(87: 2: 11)$; internal standard, phthalic acid monoanilide (PM).

concentration $(0.5-2.0 \%)$. With a mixture of acetonitrile : acetic acid : water $(80: 10: 10)$, however, the two compounds were readily eluted with the resolution and retention volume of $\operatorname{ErA}, 1.71$ and $12.0 \mathrm{ml}$, respectively. Thus the unconditioned column could be used in combination with increased concentration of acetic acid but may not be recommendable for the routine analyses because high concentration of acetic acid is considered to be deteriorative for the apparatus.

Figure 1 shows a typical chromatogram obtained in this study. ErA, AsA and phthalic acid monoanilide were eluted at 4.6, 6.0 and $13.0 \mathrm{~min}$, respectively. In this chromatogram, AsA and ErA are clearly separated from each other, with a separation factor of 1.40 and resolution of 1.56 .

Five percent metaphosphoric acid, which is a useful deproteinizer, is widely used as an extracting solvent for AsA in biological samples. However, direct injection of the extract with $5 \%$ metaphosphoric acid resulted in a gradual decrease in the flow rate and thus a considerable increase in the retention volume. These 


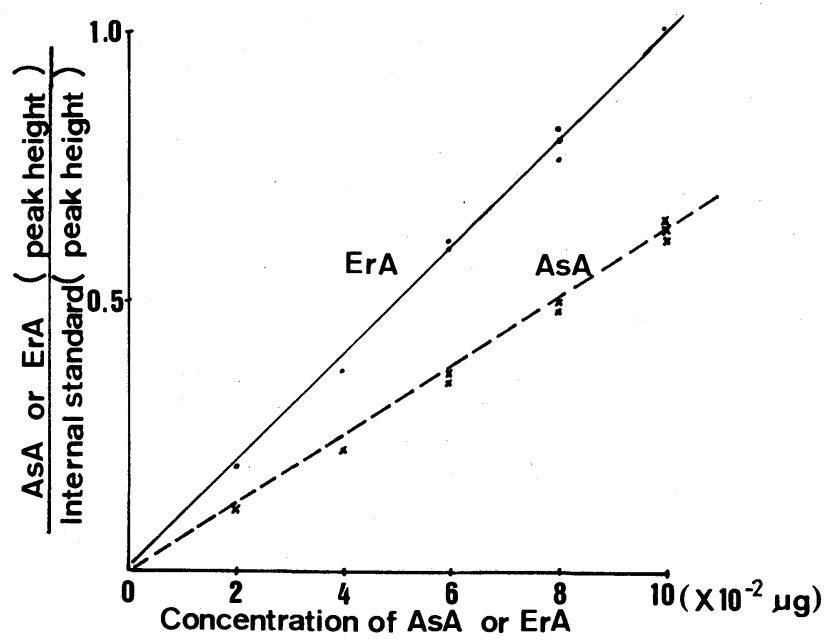

Fig. 2. Standard curve for chromatographic analysis.
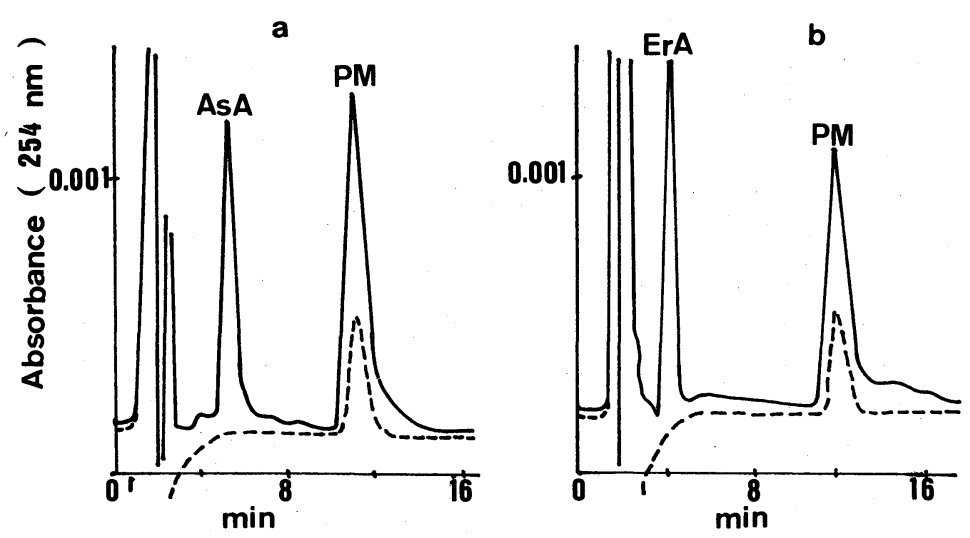

Fig. 3. Chromatograms of dehydro-AsA and dehydro-ErA before and after treatment.

(a) Dehydro-AsA reduced with $\mathrm{H}_{2} \mathrm{~S}$ to AsA (-), dehydro-AsA (---), (b)

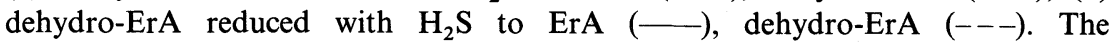
chromatographic conditions are the same as those given in Table 1.

undesirable changes could be avoided by diluting the concentration of metaphosphoric acid to $0.5 \%$ and by limiting the maximal injection size of sample to $20 \mu \mathrm{l}$. Extraction with trichloroacetic acid was found unsuitable because it resuled in the formation of some interference peaks in the chromatograms.

Retention times of ErA, AsA and the internal standard increased slightly in some cases, though the operating conditions were kept constant. It appeared that these increases might be caused partly by a slight elevation of column temperature, but mainly by changes occurring in the characteristics of column packing during prolonged operation. This situation was rectified by adding a small volume $(0.01-$ 
Table 2. Recovery of AsA and ErA from dehydro-AsA and dehydro-ErA with $\mathrm{H}_{2} \mathrm{~S}$ treatment.

\begin{tabular}{cccc}
\hline Sample & Concentration & DNP $^{\mathrm{a}}$ & HPLC \\
\hline & $(\mu \mathrm{g} / \mathrm{ml})$ & $(\mu \mathrm{g} / \mathrm{ml})$ & $(\mu \mathrm{g} / \mathrm{ml})$ \\
Dehydro-AsA & $(3.80)$ & $3.73 \pm 0.12$ & $3.72 \pm 0.16$ \\
Dehydro-ErA & $(3.80)$ & $3.96 \pm 0.08$ & $3.88 \pm 0.26$ \\
\hline
\end{tabular}

a AsA or ErA was determined by the 2,4-dinitrophenylhydrazine method.

$0.05 \%$ ) of $0.1 \mathrm{M}$ ammonium monophosphate solution to the eluant system.

As shown in Fig. 2, the calibration curves of the standard solution gave good linearity, but occasionally a small fluctuation in values of their slopes was observed. The standard deviation from the linear line was found to be $\pm 3.3 \%$. The minimum amount of AsA or ErA detectable by this method, giving a peak height of $1 \times 10^{-4}$ absorbance at $254 \mathrm{~nm}$, was about $1.0 \times 10^{-2} \mu \mathrm{g}$.

Figure 3 shows chromatograms of AsA and ErA produced from their dehydroforms by reduction with $\mathrm{H}_{2} \mathrm{~S}$. Table 2 compares their recoveries as determined by the HPLC method and by the 2,4-dinitrophenylhydrazine method. Reduction with $\mathrm{H}_{2} \mathrm{~S}$ was found to be almost complete under the experimental conditions and no significant difference was observed between the two determination methods.

The HPLC method described has the following advantages: 1) AsA and ErA are distinctly separated from each other and quantitated. 2) The analysis can be completed within 15 min. 3) Micro-quantities ( $\left.c a \cdot 10^{-2} \mu \mathrm{g}\right)$ of AsA and ErA can be easily determined with high precision.

Therefore, the HPLC method described is well suited to the separation and determination of AsA and ErA, and is regarded to be highly sensitive and with sufficient reproducibility to be applied for the analysis of biological samples. The application to various biological samples will be reported in the following paper.

\section{REFERENCES}

1) Hornig, D. (1977): Interaction of erythorbic acid with ascorbic acid catabolism. Acta Vitaminol. Enzymol. (Milano), 31, 9-14.

2) Pelletier, O., and Godin, C. (1969): Vitamin C activity of D-isoascorbic acid for the guinea pig. Can. J. Physiol. Pharmacol., 47, 985-991.

3) Miki, T., and Sahashi, Y. (1962): Paper chromatographic separation of L-ascorbic acid and D-araboascorbic acid. Vitamins (in Japanese), 25, 171-177.

4) Miki, T., and Sahashi, Y. (1962): Paper chromatographic separation and estimation of L-ascorbic acid and D-araboascorbic acid. Vitamins (in Japanese), 25, 178-182.

5) Brenner, G. S. (1964): Isomerization of the ascorbic acids. J. Org. Chem., 29, 2389.

6) Pelletier, O. (1969): Differential determination of D-isoascorbic acid and L-ascorbic acid in guinea pig organs. Can J. Biochem., 47, 449-453.

7) Mayer Freed, Chairman (1966): Methods of Vitamin Assay, Association of Official 
Vitamin Chemists, 3rd ed., Interscience Publ., New York, pp. 317-332.

8) Pachla, L. A., and Kissinger, P. T. (1976): Determination of ascorbic acid in foodstuffs, pharmaceuticals, and body fluids by liquid chromatography with electrochemical detection. Anal. Chem., 48, 364-367.

9) Williams, R. C., Baker, D. R., and Schmit, J. A. (1973): Analysis of water-soluble vitamins by high-speed ion-exchange chromatography. J. Chromatogr. Sci., 11, $618-624$.

10) Thrivikraman, K. V., Refshauge, C., and Adams, R. N. (1974): Liquid chromatographic analysis of nanogram quantities of ascorbate in brain tissue. Life Sci., 15, 1335-1342.

11) Sood, S. P., Sartori, L. E., Wittmer, D. P., and Haney, W. G. (1976): High pressure liquid chromatographic determination of ascorbic acid in selected foods and multivitamin products. Anal. Chem., 48, 796-798.

12) Wills, R. B. H., Sham, C. G., and Day, W. R. (1977): Analysis of water soluble vitamins by high performance liquid chromatography. J. Chromatogr. Sci., 15, 262-266. 